\title{
Enhanced cytotoxicity of human hepatocellular carcinoma cells following pretreatment with sorafenib combined with trichostatin A
}

\author{
JOHN CHUN-HAO CHEN ${ }^{1,2}$, HUI-YEN CHUANG ${ }^{1}$, YI-JEN LIAO ${ }^{3}$, FEI-TING HSU ${ }^{4}$, \\ YEN-CHUNG CHEN $^{5}$, WEI-HSUN WANG ${ }^{6}$ and JENG-JONG HWANG ${ }^{1}$
}

\author{
${ }^{1}$ Department of Biomedical Imaging and Radiological Sciences, National Yang Ming University, Taipei 112; \\ ${ }^{2}$ Department of Radiation Oncology, Mackay Memorial Hospital, Taipei 251; ${ }^{3}$ School of Medical Laboratory and \\ Biotechnology, Taipei Medical University; ${ }^{4}$ Department of Medical Imaging, Taipei Medical University Hospital, Taipei 110; \\ ${ }^{5}$ Department of Pathology, National Yang Ming University Hospital, Yilan 260; ${ }^{6}$ Department of Orthopedic Surgery, \\ Changhua Christian Hospital, Changhua 500, Taiwan, R.O.C.
}

Received July 2, 2016; Accepted April 27, 2018

DOI: $10.3892 / 01.2018 .9582$

\begin{abstract}
Trichostatin A (TSA), a hydroxamate histone deacetylase inhibitor, is a compound that has been identified to induce anticancer activity. The aim of the present study was to investigate whether sorafenib, in combination with TSA, was able to augment the anticancer effects of TSA, identifying an optimum treatment time plan and the potential underlying molecular mechanisms involved in human hepatocellular carcinoma (HCC) in vitro. Huh7/nuclear factor- $\kappa \mathrm{B}$ $(\mathrm{NF}-\kappa \mathrm{B})-l u c 2$ cells were treated with TSA or sorafenib alone, or sorafenib, prior to, in combination with or following TSA

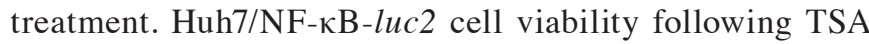
treatment was determined using an MTT assay, and NF- $\kappa \mathrm{B}$ activity was analyzed. In addition, the expression levels of $\mathrm{NF}-\kappa \mathrm{B}$-regulated downstream effector proteins were assayed by western blotting. Inhibitors of mitogen-activated protein kinases (MAPKs), protein kinase B (AKT) and mutant inhibitor of NF- $\kappa \mathrm{B} \alpha(\mathrm{I} \kappa \mathrm{B} \alpha \mathrm{M})$ vectors were used to confirm the function of the $\mathrm{NF}-\kappa \mathrm{B}$ signal transduction pathways in response to the effects of sorafenib combined with TSA against HCC. The results of the present study indicated that
\end{abstract}

Correspondence to: Professor Jeng-Jong Hwang, Department of Biomedical Imaging and Radiological Sciences, National Yang Ming University, 155, Section 2, Li-Nong Street, Taipei 112, Taiwan, R.O.C.

E-mail: jjhwang@ym.edu.tw

Abbreviations: HCC, hepatocellular carcinoma; TSA, trichostatin A; ERK, extracellular-signal-regulated kinase; MMP-9, matrix metalloproteinase 9; VEGF, vascular endothelial growth factor; XIAP, X-linked inhibitor of apoptosis protein; Bcl-2, B-cell lymphoma $2 ; \Delta \Psi \mathrm{m}$, mitochondrial membrane potential

Key words: hepatocellular carcinoma, sorafenib, trichostatin A, extracellular-signal-regulated kinase, nuclear factor- $\mathrm{\kappa} B$ pre-treatment with sorafenib followed by TSA inhibited the cell viability compared with other treatment modalities, and prevented TSA-induced extracellular-signal-regulated kinase $(\mathrm{ERK}) / \mathrm{NF}-\kappa \mathrm{B}$ activity and expression of downstream effector proteins. It was further demonstrated that $\mathrm{I} \kappa \mathrm{B} \alpha \mathrm{M}$ vector sensitized Huh7/NF- $\kappa \mathrm{B}-l u c 2$ cells to TSA, thus it was possible to reverse TSA-induced $\mathrm{NF}-\kappa \mathrm{B}$ activity using PD98059, a MAPK/ERK kinase inhibitor. In conclusion, sorafenib pre-treatment may increase the efficacy of subsequent TSA treatment in HCC. Furthermore, sorafenib pre-treatment is hypothesized to sensitize HCC to TSA via the inhibition of the $\mathrm{MEK} / \mathrm{ERK} / \mathrm{NF}-\kappa \mathrm{B}$ signal transduction pathway.

\section{Introduction}

Histone deacetylase inhibitors (HDACIs) are compounds that regulate the alteration of chromatin structure and subsequent gene expression in cancer cells, and are recognized as potential novel antitumor agents (1). HDACIs have emerged as a promising class of anticancer agents, leading to the approval by the USA Food and Drug Administration (FDA) of vorinostat [suberoylanilide hydroxamic acid (SAHA)] for the treatment of cutaneous T-cell lymphoma. In addition, other HDACIs, including panobinostat, belinostat and entinostat, are currently being investigated as potential monotherapeutic agents for use in combination with other antitumor therapies in clinical trials (2). Entinostat (MS-275), a potent class of HDACIs currently in use in preclinical studies $(3,4)$, induces apoptosis through the activation of caspase-3, upregulation of B-cell lymphoma 2 (Bcl-2)-associated X protein and downregulation of $\mathrm{Bcl}-2$. A Phase I study of entinostat combined with sorafenib was conducted in 31 patients with advanced solid tumors in various types of cancer, including colorectal cancer, non-small cell lung cancer (NSCLC), sarcoma, esophageal/gastroesophageal junction cancer, thyroid cancer and melanoma (5). Although the clinical benefits of entinostat for hepatocellular carcinoma (HCC) were not specifically stated in this Phase I study, the combination of entinostat 
and sorafenib treatment was effectively tolerated. However, the benefit of this combinatorial therapy, which functions via cytotoxic synergy, has been demonstrated in a number of cancer cell lines including U2-OS sarcoma, H226, MV 522 and H157 NSCLC and HepG2 (5). Furthermore, a previous study demonstrated that the combination of SAHA and sorafenib enhanced anti-proliferative activity in HCC cells in vitro (6). Notably, the suppression of autophagy increased the inhibitory effects of SAHA and sorafenib, alone or in combination on HCC cell growth. 3-(1-benzenesulfonyl-2,3-dihydro- $1 H$-indol-5-yl)- $N$-hydroxyacrylamide (MPT0E028) is an orally available $N$-hydroxyacrylamide-derived HDACI that has been demonstrated to elicit an increased degree of anticancer activity compared with vorinostat (7). The effects of sorafenib in combination with MPT0E028 synergistically decreased liver cancer cell viability and significantly improved the tumor growth delay in a human hepatoma cell line (Hep3B) xenograft model, by increased apoptotic cell death (8). MPT0E028 altered the modifications of histone and non-histone proteins, whereas sorafenib blocked MPTOE028-induced extracellular-signal-regulated kinase (ERK) activation and its downstream signaling cascades including signal transducer and activation of transcription 3 phosphorylation and induced myeloid cell differentiation protein upregulation, suggesting that the synergistic interaction between MPT0E028 and sorafenib occurs at least in part through the inhibition of ERK signaling.

Trichostatin A (TSA) and SAHA are hydroxamate HDACIs, and have been identified to trigger cell cycle arrest and apoptosis through the induction of tumor suppressor gene expression in a number of types of cancer cell $(9,10)$. SAHA has been approved by the FDA for the treatment of cutaneous T-cell lymphoma (11). TSA is proposed as a potential anticancer drug that activates p53, p21 and p27, subsequently resulting in tumor growth inhibition in liver, breast and gastric cancers (12-14).

Constitutive activation of nuclear factor- $\kappa \mathrm{B}(\mathrm{NF}-\kappa \mathrm{B})$ is observed in a number of types of tumor tissue and is associated with aggressive tumor progression $(15,16)$. The expression of matrix metalloproteinase 9 (MMP-9), vascular endothelial growth factor (VEGF), X-linked inhibitor of apoptosis protein (XIAP) and B-cell lymphoma 2 (Bcl-2) induced by NF- $\kappa \mathrm{B}$ are suppressed by chemotherapeutic agents. Furthermore, these agents augment the therapeutic efficacy via the blockade of NF- $\mathrm{BB}$-mediated chemoresistance in vitro and in vivo (17-19). Notably, HDACIs increase the activation and expression of pro-apoptotic proteins including caspases $3 / 8$ and cytochrome $c$, and activate

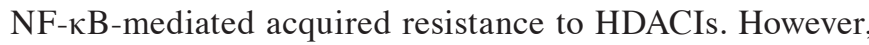
it is possible to suppress acquired resistance to HDACIs in cancer, using NF- $\mathrm{kB}$ inhibitors $(9,14,20,21)$.

Sorafenib, a targeted drug for multi-kinase inhibition approved by the FDA for renal carcinoma, inhibits NF- $\mathrm{BB}$ activity induced by $12-O$-tetradecanoylphorbol-13-acetate and radiation, in human $\mathrm{HCC}$ and colorectal cancer-bearing animal models $(22,23)$. In a previous study, our group demonstrated that sorafenib increases the therapeutic efficacy of SAHA against HCC; through the inhibition of SAHA-induced ERK/NF- $\kappa B$ signaling pathways in a human HCC-bearing animal model (21). However, whether sorafenib is able to enhance the antitumor effects of TSA in HCC has not been fully elucidated. To the best of our knowledge, the present study is the first to evaluate the potential synergistic effects of sorafenib in combination with TSA in human HCC in vitro. The purpose of the present study was to identify the optimal time schedule and underlying mechanisms of sorafenib treatment in combination with TSA against human HCC in Huh7/ NF-кB-luc2 cells.

\section{Materials and methods}

Chemicals. TSA was obtained from Sigma-Aldrich (Merck KGaA, Darmstadt, Germany). For in vitro experiments, a $10 \mathrm{mM}$ solution of TSA in absolute ethanol was prepared and stored at $20^{\circ} \mathrm{C}$ until use. Sorafenib was extracted from Nexavar tablet (Bayer Healthcare Co., Leverkusen, Germany) as described previously (23).

Cell culture. The human Huh7 hepatocellular carcinoma cell line was provided by Dr Jason Chia-Hsien Cheng (Department of Radiation Oncology, National Taiwan University Hospital, Taipei, Taiwan). Cells were cultured in Dulbecco's modified Eagle's medium (DMEM; cat. no. SH30022.02; HyClone Laboratories, GE Healthcare Life Sciences, Logan, UT, USA) supplemented with $10 \%$ fetal bovine serum (FBS; Hyclone), $100 \mathrm{U} / \mathrm{ml}$ penicillin and $100 \mu \mathrm{g} / \mathrm{ml}$ streptomycin at $37^{\circ} \mathrm{C}$ in a humidified incubator containing $5 \% \mathrm{CO}_{2}$. The Huh7/NF-кB-luc2 stable clone was cultured using the same method as described above for Huh7 cells, with the addition of $500 \mu \mathrm{g} / \mathrm{ml}$ geneticin (Calbiochem; Merck KGaA).

Construction of NF- $\kappa B / l u c 2$ vector. pGL4-luc2 vector (Promega Corporation, Madison, WI, USA) was digested with AseI and $B s A \mathrm{I}$, then using the Klenow enzyme to produce the blunted end. The NF- $\kappa \mathrm{B}$-responsive elements were isolated from a pNF- $\mathrm{kB}-l u c$ vector (Clontech Laboratories, Inc., Mountain View, CA, USA) by MluI and HindIII, and then using the Klenow enzyme to produce the blunted end. The NF- $\mathrm{kB}$-responsive element was inserted and ligated into digested pGL4-luc2, resulting in a pNF-кB-luc2 vector.

Plasmid transfection and stable clone selection. The transfection of Huh7 was performed using jetPEI ${ }^{\mathrm{TM}}$ DNA transfection reagent (Polyplus Transfection, New York, NY, USA). A total of $2 \times 10^{6}$ cells were seeded in a $100 \mathrm{~mm}$ diameter dish $24 \mathrm{~h}$ prior to transfection. Subsequently, $8 \mu \mathrm{g}$ pNF-кB-luc2 vector DNA and $16 \mu \mathrm{l}$ jetPEI solution were diluted in $500 \mu 1145 \mu \mathrm{M}$ $\mathrm{NaCl}$, and then immediately mixed together and incubated for $30 \mathrm{~min}$ at room temperature. The jetPEI/DNA mixture was added to the cells in the $100 \mathrm{~mm}$ dish, which was then incubated at $37^{\circ} \mathrm{C}$ for $24 \mathrm{~h}$. Cells were then trypsinized and cultured with DMEM containing $1 \mathrm{mg} / \mathrm{ml} \mathrm{G} 418$ supplemented with 10\% FBS for 2 weeks. The surviving clones were isolated and expanded to sufficient numbers to satisfy the following culture conditions: $1 \times 10^{6}, 5 \times 10^{5}, 3 \times 10^{5}, 1 \times 10^{5}, 5 \times 10^{4}, 3 \times 10^{4}$ and $1 \times 10^{4}$ cells/well in 96 -well plate, in order to calculate the photons emitted from one cell and select the stable clone to use. Cells were incubated with $500 \mu \mathrm{M}$ D-luciferin at $37^{\circ} \mathrm{C}$ for $15 \mathrm{~min}$, and signals were acquired for $1 \mathrm{~min}$ with a IVIS50 
Imaging System (Xenogen; Caliper Life Sciences, Hopkinton, MA, USA). Regions of interest were drawn around each well and quantified as photon (s)/cell using Living Image software (Version 2.20, Xenogen, Caliper Life Sciences). The Luc2 protein expression in each clone was assayed using bioluminescent imaging (BLI) as later described. Cells in those clones with $\geq 3$ photons (s)/cell were used in the present study. The recombinant bioluminescent cell clone was renamed as Huh7/NF- $\mathrm{BB}-l u c 2$ cell line (22). A mutant inhibitor of NF- $\kappa \mathrm{B} \alpha(\mathrm{I} \kappa \mathrm{B} \alpha \mathrm{M})$ vector (p-I $\mathrm{B} \alpha \mathrm{M}$; Clontech Laboratories, Inc.) was used as the positive control for the suppression of NF- $\mathrm{\kappa B}$ activity as described previously (21).

MTT assay. Huh7/NF-кB-luc2 cells were cultured in DMEM supplemented with $10 \%$ FBS in 96-well plates at a density of $3 \times 10^{4}$ cells/well for $24 \mathrm{~h}$, followed by TSA treatment at different concentrations (between 0 and $4 \mu \mathrm{M}$ ) for a further 24 and $48 \mathrm{~h}$ at $37^{\circ} \mathrm{C} \mathrm{(24).} \mathrm{Following} \mathrm{culture,} \mathrm{cells} \mathrm{were} \mathrm{washed}$ with fresh medium followed by the addition of MTT solution $(100 \mu 1$ at $5 \mathrm{mg} / \mathrm{ml})$ into each well and incubated for $4 \mathrm{~h}$ at $37^{\circ} \mathrm{C}$. Following removal of the MTT solution, cells were exposed to $100 \mu 1$ dimethylsulfoxide (DMSO) for $5 \mathrm{~min}$, and plates were scanned with an ELISA plate reader (PowerWave X340; BioTek, Winooski, VT, USA) using a test wavelength of $570 \mathrm{~nm}$ and a reference wavelength of $630 \mathrm{~nm}$.

$N F-\kappa B$ luciferase reporter gene assay using BLI. Huh7/NF- $\kappa \mathrm{B}-l u c 2$ cells demonstrated $\sim 80 \%$ confluency in a $75-\mathrm{cm}^{2}$ culture dish at a density of $5 \times 10^{6}$ cells/dish. Therefore, Huh7/NF-кB-luc 2 cells were plated out at a density of $3 \times 10^{4}$ cells/well in 96 -well plates in the present study. Cells were cultured in DMEM supplemented with 10\% FBS in 96 -well plates at $37^{\circ} \mathrm{C}$ for $24 \mathrm{~h}$, and then treated with different concentrations of TSA (between 0 and $4 \mu \mathrm{M}$ ) for a further $24 \mathrm{~h}$ and $48 \mathrm{~h}$ at $37^{\circ} \mathrm{C}$. For the initial experiment, cells were treated with vehicle (DMEM with 10\% FBS and $0.01 \%$ absolute alcohol), TSA $(1 \mu \mathrm{M})$, sorafenib $(10 \mu \mathrm{M})$, and a combination of sorafenib $(10 \mu \mathrm{M})$ and TSA $(1 \mu \mathrm{M})$ for $48 \mathrm{~h}$. Additionally, to verify which MAPK inhibitor affected

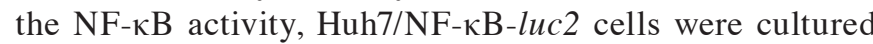
in DMEM supplemented with 10\% FBS in 96-well plates at $37^{\circ} \mathrm{C}$ for $24 \mathrm{~h}$, then treated with inhibitors of mitogen-activated protein kinase (MAPK)/ERK kinase (MEK; PD98059; cat. no. tlrl-pd98; InvivoGen, Hong Kong, China), protein kinase B (Akt; 1L-6-hydroxymethyl-chiro-inositol-2-(R)-2-O-methyl3-O-octadecyl-sn-glycerocarbonate, cat. no. 1701-1, BioVision, Inc., Milpitas, CA, USA), c-Jun N-terminal kinase (JNK; SP600125, cat. no. 8177s, Cell Signaling Technology, Inc., Danvers, MA, USA) and p38 (SB203580, cat. no. 5633s; Cell Signaling Technology, Inc.) for another $48 \mathrm{~h}$. The activity of NF- $\kappa \mathrm{B}$ was determined by BLI. D-luciferin $(100 \mu \mathrm{l} ; 500 \mu \mathrm{M}$; Xenogen; Caliper Life Sciences) was added to each well, and images were captured for 1 min using an IVIS50 Imaging System (Xenogen; Caliper Life Sciences). Signals were quantified as photons/sec, and compared with that of DMSO-treated controls to obtain the relative NF- $\mathrm{kB}$ activity using Living Image software (Version 2.20; Xenogen; Caliper Life Sciences).

The treatment schedules for Huh7/NF- $\kappa B$-luc2 cells treated with TSA, sorafenib and combined TSA and sorafenib.
Huh7/NF-кB-luc2 cells were cultured in DMEM supplemented with $10 \%$ FBS in 96-well plates at a density of $3 \times 10^{4}$ cells/well for $24 \mathrm{~h}$ at $37^{\circ} \mathrm{C}$, followed by various treatments: Cells were treated with vehicle (DMEM with $10 \%$ FBS and $0.01 \%$ absolute alcohol) for $48 \mathrm{~h}$; TSA $(1 \mu \mathrm{M})$ for $48 \mathrm{~h}$; sorafenib $(10 \mu \mathrm{M})$ for $48 \mathrm{~h}$; TSA $(1 \mu \mathrm{M})$ for $24 \mathrm{~h}$ followed by sorafenib $(10 \mu \mathrm{M})$ for a further $24 \mathrm{~h}$; or concurrent TSA $(1 \mu \mathrm{M})$ plus sorafenib $(10 \mu \mathrm{M})$ for $48 \mathrm{~h}$; and sorafenib $(10 \mu \mathrm{M}) 24 \mathrm{~h}$ prior to TSA $(1 \mu \mathrm{M})$ for $24 \mathrm{~h}$. All the aforementioned treatments were performed at $37^{\circ} \mathrm{C}$. Following the treatments, cells were assayed for the viability by MTT assay as follows: Cells were washed with DMEM followed by the addition of MTT solution (100 $\mu \mathrm{l}$ at $5 \mathrm{mg} / \mathrm{ml})$ into each well and incubated for $4 \mathrm{~h}$ at $37^{\circ} \mathrm{C}$. Following removal of the MTT solution, cells were exposed to $100 \mu \mathrm{l}$ DMSO for $5 \mathrm{~min}$ at room temperature, and plates were scanned with an ELISA plate reader (PowerWave X340) using a test wavelength of $570 \mathrm{~nm}$ and a reference wavelength of $630 \mathrm{~nm}$. The relative NF- $\mathrm{BB}$ activity was determined by BLI. D-luciferin (100 $\mu \mathrm{l}$; $500 \mu \mathrm{M}$; Xenogen; Caliper Life Sciences) was added to each well, and images were captured for $1 \mathrm{~min}$ using an IVIS50 Imaging System (Xenogen; Caliper Life Sciences). Signals were quantified as photons/sec, and compared with that of DMSO-treated controls to obtain the relative NF- $\kappa B$ activity using Living Image software (version 2.20; Xenogen; Caliper Life Sciences).

Western blotting. Huh7/NF-кB-luc2 cells were seeded $\left(2 \times 10^{6} \mathrm{cells} / \mathrm{dish}\right)$ into $10-\mathrm{cm}$ diameter dishes and incubated for $24 \mathrm{~h}$, prior to transfection with empty and IкB $\alpha \mathrm{M}$ vectors, and treatment with TSA $(1 \mu \mathrm{M})$ for $48 \mathrm{~h}$. Additionally, cells were treated with TSA $(1 \mu \mathrm{M})$, sorafenib $(10 \mu \mathrm{M})$, and a combination of TSA $(1 \mu \mathrm{M})$ and sorafenib $(10 \mu \mathrm{M})$ for $48 \mathrm{~h}$ at $37^{\circ} \mathrm{C}$. Cells from each treatment group were then harvested for total protein extraction and analyzed by western blotting. Lysis buffer $(50 \mathrm{mM}$ Tris/ $\mathrm{HCl}, \mathrm{pH} 8.0,120 \mathrm{mM} \mathrm{NaCl}$, $0.5 \% \mathrm{NP}-40$ and $1 \mathrm{mM}$ phenylmethanesulfonylfluoride; $4^{\circ} \mathrm{C}$ for $\sim 1 \mathrm{~h}$ ) was used for the extraction of total proteins from cells. The proteins ( $40 \mu \mathrm{g} / \mathrm{lane})$ were separated via SDS-PAGE $(10 \%$ gel) and transferred onto a polyvinylamide difluroide membrane (Millipore, Billerica, MA, USA). The membrane was blocked with 5\% non-fat milk in TBST buffer solution (10 mM Tris-base, $150 \mathrm{mM} \mathrm{NaCl}, 0.1 \%$ Tween-20) for $1 \mathrm{~h}$ at room temperature, followed by incubation with the appropriate primary antibodies against MMP-9 (1:1,000; cat. no. AB19016), VEGF (1:2,000; cat. no. ABS82), XIAP (1:2,000; cat. no. ab21278; Abcam, Cambridge, UK), Bcl-2 (1:2,000; cat. no. 05/729), total (T)-ERK (1:2,000; cat. no. 05-1152), phosphorylated (P)-ERK (1:5,000; cat. no. 9106; Cell Signaling Technology, Inc.), cleaved caspase-3 (1:5,000; cat. no. MAB10753) and $\beta$-actin $(1: 1,000$; cat. no. MABT523) overnight at $4^{\circ} \mathrm{C}$. Antibodies against the aforementioned proteins were purchased from EMD Millipore (Billerica, MA, USA) unless specified otherwise. Membranes were further incubated for $1 \mathrm{~h}$ at room temperature with horseradish peroxidase-conjugated goat anti-rabbit secondary antibodies. Protein expression was detected using an enhanced chemiluminescence system and Image J software (version 1.50i, National Institute of Health, Bethesda, MA, USA) was used for quantification. 

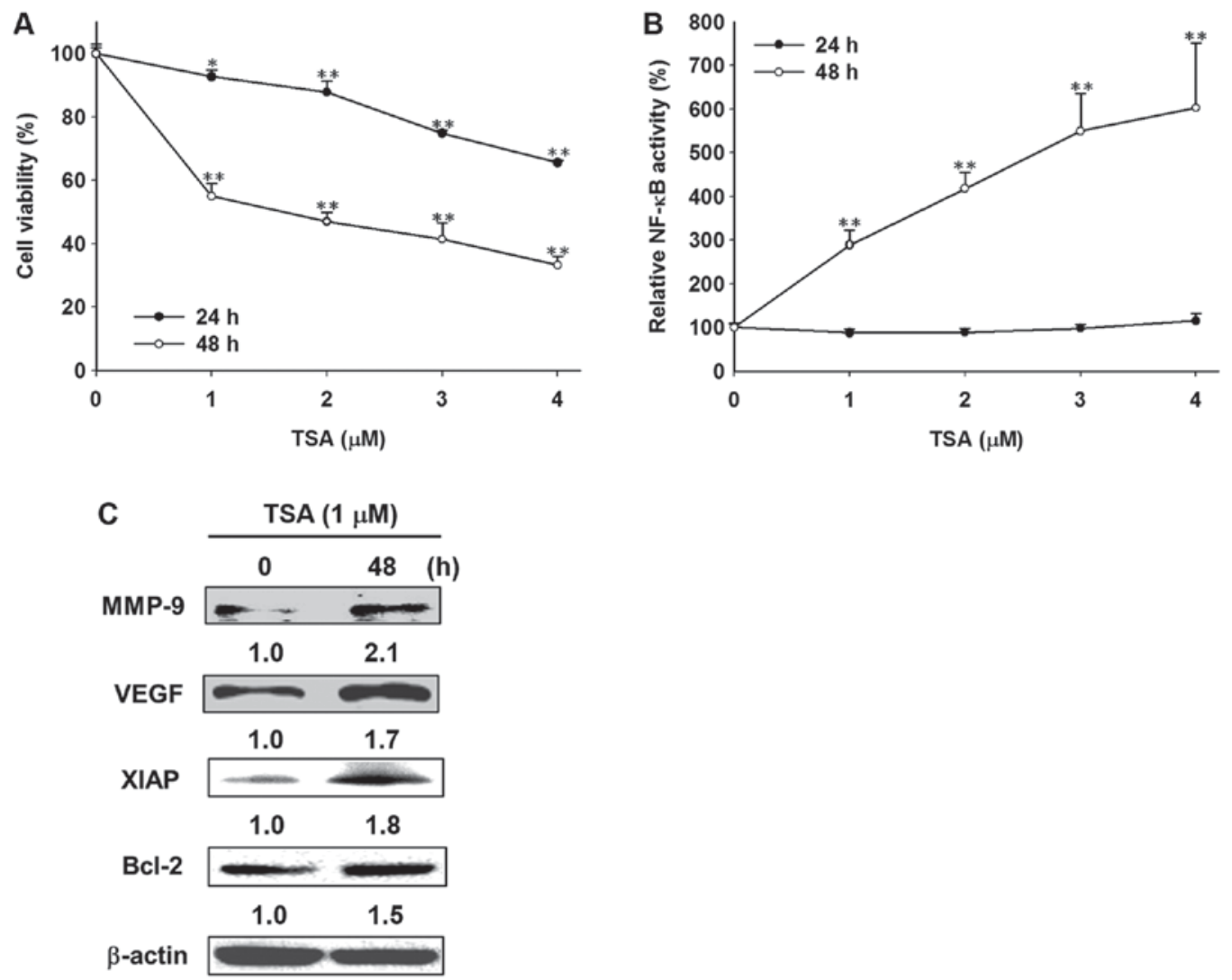

Figure 1. Effects of TSA treatment on cell viability, NF- $\kappa$ B activity and its downstream effector proteins in Huh7/NF- $\kappa$ B-luc2 cells. (A) The cytotoxicity of TSA was determined using an MTT assay. (B) NF- $\kappa$ B activity was determined by bioluminescence imaging using NF- $\kappa \mathrm{B}$ as the promoter and luciferase gene as the reporter. (C) Cells were treated with TSA $(1 \mu \mathrm{M})$ for $0 \mathrm{~h}$ (control) and $48 \mathrm{~h}$, respectively. The expression of NF- $\kappa \mathrm{B}$ downstream effector proteins including VEGF, MMP-9, XIAP and Bcl-2 was assessed by western blotting. ${ }^{*} \mathrm{P}<0.05$ and ${ }^{* *} \mathrm{P}<0.01$ vs. control. TSA, trichostatin $\mathrm{A}$; NF- $\kappa \mathrm{B}$, nuclear factor- $\kappa \mathrm{B}$; VEGF, vascular endothelial growth factor; MMP-9, matrix metalloproteinase-9; XIAP, X-linked inhibitor of apoptosis protein; Bcl-2, B-cell lymphoma 2.

Mitochondrial membrane potential $\left(\Delta \Psi_{m}\right)$ assay. A total of $2 \times 10^{5}$ cells from different treatment groups were collected by centrifugation (140 x g, $5 \mathrm{~min}$ at room temperature), washed twice with PBS and resuspended in $500 \mu 1$ 3,3'-dihexylacarbocyanine iodide $(4 \mu \mathrm{M})$ and $2^{\prime}, 7^{\prime}$-dichlorofluorescin diacetate $(10 \mu \mathrm{M})$ prior to incubation at $37^{\circ} \mathrm{C}$ for $30 \mathrm{~min} . \Delta \Psi_{\mathrm{m}}$ was measured with a flow cytometer (BD Biociences, Franklin lakes, NJ, USA) using the Indo-1/AM cell permeant dye (cat. no. I-1223; Thermo Fisher Scientific, Inc.).

Statistical analysis. Paired Student's t-test was performed for comparisons between two groups. One-way analysis of variance followed by Tukey's post hoc test was performed when comparing more than two groups. All statistical analyses were performed using SPSS software (version 21.0; IBM Corp., Armonk, NY, USA). $\mathrm{P}<0.05$ was considered to indicate a statistically significant difference.

\section{Results}

TSA induces cytotoxicity, $N F-\kappa B$ activity and NF- $\kappa B$ downstream effector protein expression in Huh7/NF- $\kappa B$-luc2 cells in a time-dependent manner. Huh7/NF- $\kappa \mathrm{B}-l u c 2$ cells were treated with TSA at different concentration (between 0 and $4 \mu \mathrm{M}$ TSA) for 24 or $48 \mathrm{~h}$. The viability of Huh7/NF-кB-luc 2 cells was significantly inhibited at 24 and $48 \mathrm{~h}$ in response to TSA treatment at all concentrations (1, 2, 3 and $4 \mu \mathrm{M}$; Fig. $1 \mathrm{~A}) . \mathrm{NF}-\kappa \mathrm{B}$ activity was unchanged at $24 \mathrm{~h}$ following TSA treatment, but was significantly enhanced at $48 \mathrm{~h}$ (Fig. 1B). TSA also increased the expression of NF- $\kappa \mathrm{B}$ downstream effector proteins (MMP-9, VEGF, XIAP and Bcl-2) in Huh7/NF-кB-luc2 cells (Fig. 1C).

I $\mathrm{B} \alpha M$ vector enhances the antitumor effect of TSA in $H u h 7 / N F-\kappa B-l u c 2$ cells. An I $\kappa \mathrm{B} \alpha \mathrm{M}$ vector was utilized as an $N F-\kappa B$ inhibitor to analyze whether inhibition of $N F-\kappa B$ activation sensitized Huh7/NF- $\mathrm{B}-l u c 2$ cells to TSA. It was observed that TSA-induced decreases in cell viability and increased $\Delta \Psi_{\mathrm{m}}$ loss were significantly enhanced in I $\kappa \mathrm{B} \alpha \mathrm{M}$-transfected Huh7/NF- $\kappa \mathrm{B}-l u c 2$ cells compared with cells transfected with empty vectors (Fig. 2A and B). In addition, TSA-induced expression of $\mathrm{NF}-\kappa \mathrm{B}$ downstream effector proteins was inhibited, whereas levels of cleaved caspase-3 were increased by transfection of $\mathrm{I} \kappa \mathrm{B} \alpha \mathrm{M}$ into Huh7/NF-кB-luc2 cells (Fig. 2C).

Sorafenib enhances the antitumor effect of TSA in

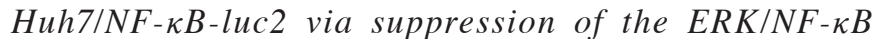
signaling pathway. The three distinct treatment regimens of sorafenib and TSA (TSA + sorafenib post-treatment, TSA + concurrent sorafenib, and sorafenib pre-treatment + TSA, respectively) were administered to verify that sorafenib influenced TSA-induced cytotoxicity and NF- $\mathrm{NB}$ activity in HCC. Cell viability was significantly decreased by sorafenib pre-treatment followed by TSA when compared with the 


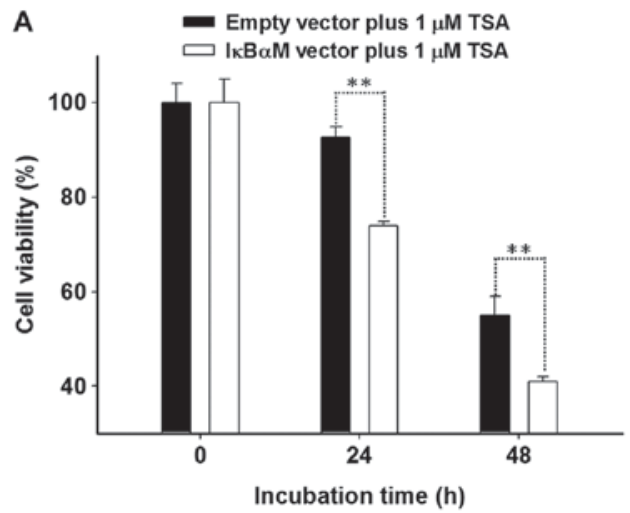

C

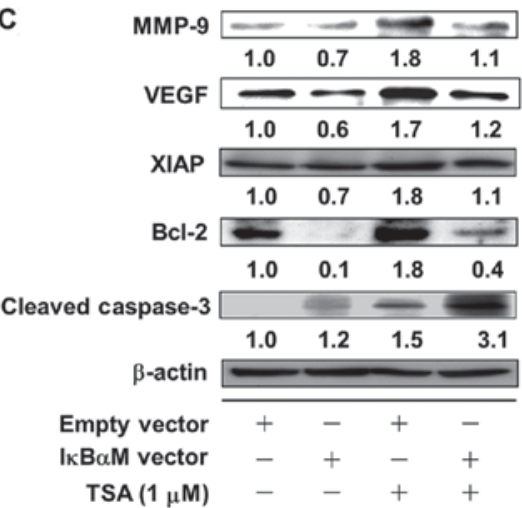

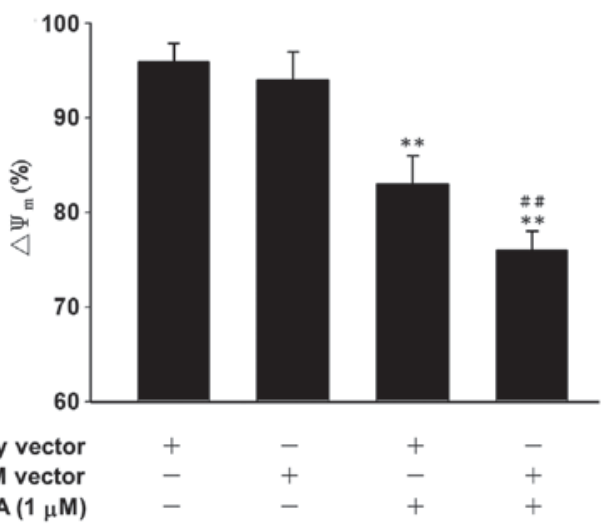

Figure 2.Effects of $\mathrm{I} \kappa \mathrm{B} \alpha \mathrm{M}$ vector transfection on TSA-induced cytotoxicity, $\Delta \Psi_{\mathrm{m}}$ and the expression of NF- $\kappa \mathrm{B}$ downstream effector proteins in Huh7/NF- $\kappa \mathrm{B}-\mathrm{luc} 2$ cells. (A) Cell viability was determined using an MTT assay. (B) $\Delta \Psi_{\mathrm{m}}$ of cells was assayed by flow cytometry following TSA treatment (1 $\left.\mu \mathrm{M}\right)$ for $48 \mathrm{~h}$. (C) The expression of NF- $\mathrm{KB}$ downstream effector proteins and cleaved caspase-3 were assayed by western blotting following TSA treatment (1 $\mu \mathrm{M})$ for

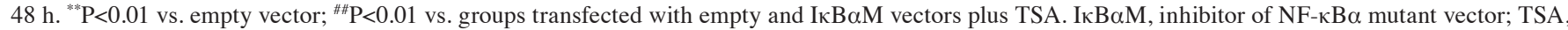
trichostatin A; NF- $\kappa$ B, nuclear factor- $\kappa \mathrm{B} ; \Delta \Psi_{\mathrm{m}}$, mitochondrial membrane potential; MMP-9, matrix metalloproteinase-9; VEGF, vascular endothelial growth factor; XIAP, X-linked inhibitor of apoptosis protein; Bcl-2, B-cell lymphoma 2.

decreases resulting from the other treatment schedules (concurrent and post-treatment) in Huh7/NF- $\mathrm{kB}-l u c 2$ cells (Fig. 3A). Pre-treatment with sorafenib followed by TSA significantly inhibited TSA-induced NF- $\kappa$ B activity when compared with the inhibition observed following concurrent sorafenib plus TSA or sorafenib post-treatment with TSA in Huh7/NF-kB-luc2 cells (Fig. 3B). ERK, AKT, JNK and p38 inhibitors were used in the present study to elucidate the downstream pathway/underlying molecular mechanism by which sorafenib suppressed TSA-induced NF- $\kappa \mathrm{B}$ activity in Huh7/NF- $\kappa \mathrm{B}-l u c 2$ cells. The results revealed that Huh7/NF-кB-luc2 cells treated with an ERK inhibitor significantly decreased TSA-induced NF-kB activity (Fig. 3C, lane 9, compared with lane 7). TSA-induced ERK phosphorylation was inhibited by sorafenib pre-treatment in Huh7/NF-кB-luc2 cells (Fig. 3D, lane 4 compared, with lane 3). TSA-induced expression of NF-кB downstream effector proteins, including MMP-9, VEGF, XIAP, Bcl-2, were inhibited, whereas cleaved caspase-3 was increased by sorafenib pre-treatment followed by TSA in Huh7/NF-кB-luc2 cells (Fig. 3D, lane 4, compared with lane 3).

\section{Discussion}

Induction of NF- $\mathrm{\kappa B}$ activity in cancer cells by TSA may result in treatment resistance, whereas suppression of NF- $\mathrm{kB}$ activation may enhance the anticancer effect of TSA in several human cancer cells $(9,14,25)$. The results of the present study

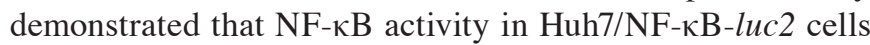
was induced after $48 \mathrm{~h}$ of TSA treatment. Sorafenib, a multikinase inhibitor, has previously been demonstrated to enhance the antitumor effects of SAHA in HCC in vitro and in vivo; via Fas-associated death domain-like interleukin-1 $\beta$-converting enzyme suppression, cluster of differentiation 95 activation and the inhibition of ERK/NF- $\mathrm{KB}$ signaling pathways $(10,21)$. However, it is unknown whether sorafenib sensitizes HCC cells further, which are vulnerable to the cytotoxicity effects of TSA and to elucidate the underlying molecular mechanisms involved. In the present study, the IкB $\alpha \mathrm{M}$ vector used represented a positive control to verify the inhibition of NF- $\kappa \mathrm{B}$ activity on the anticancer effects of TSA in Huh7/NF-kB-luc2 cells. Transfection of the I $\kappa \mathrm{B} \alpha \mathrm{M}$ vector significantly increased TSA-induced cytotoxicity, and significantly decreased the $\Delta \Psi_{\mathrm{m}}$, following TSA treatment with or without I $\mathrm{I} B \alpha \mathrm{M}$ vector transfection compared with that of the sham group. The $\Delta \Psi_{\mathrm{m}}$ of cells transfected with the I $\kappa \mathrm{B} \alpha \mathrm{M}$ vector followed by TSA treatment was significantly decreased compared with that treated with TSA alone. Furthermore, expression of NF- $\kappa \mathrm{B}$ downstream effector proteins including MMP-9, VEGF, XIAP and Bcl-2 were suppressed, whereas cleaved caspase- 3 was increased, following TSA treatment; the effect of which was enhanced when pretreated with IкB $\alpha \mathrm{M}$ vector transfection. 
A
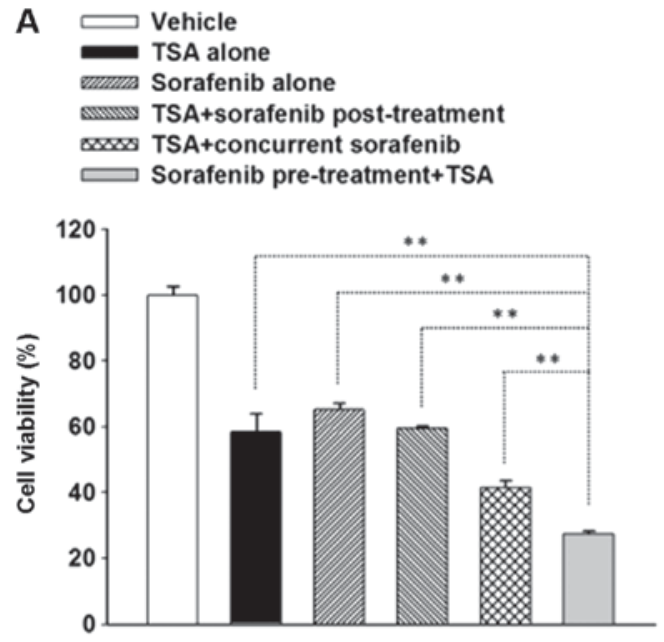

C

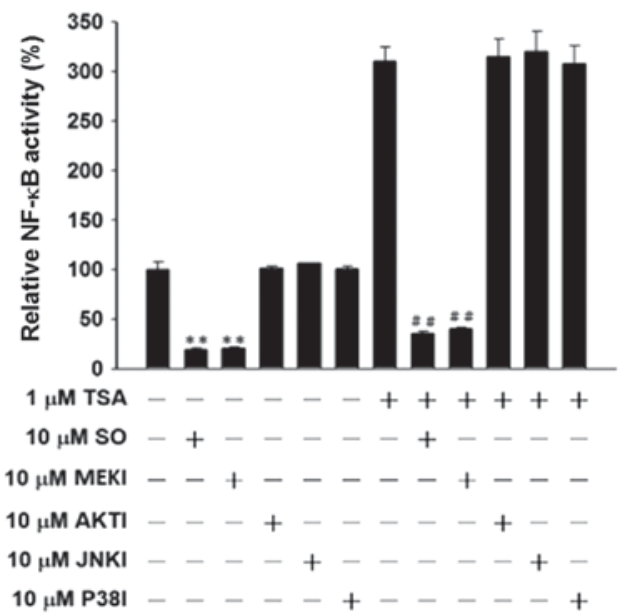

B
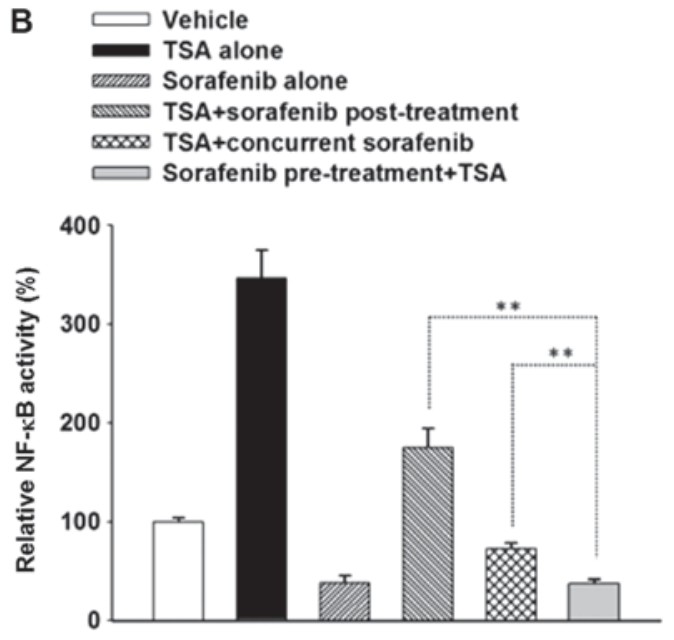

D
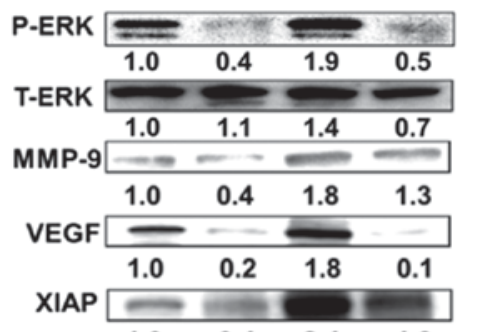

$\begin{array}{llll}1.0 & 0.4 & 2.4 & 1.3\end{array}$

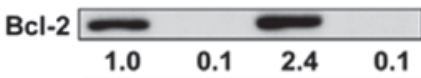

\begin{tabular}{rlllll|} 
Cleaved caspase-3 & 1.0 & 0.1 & 2.4 & 0.1 \\
\cline { 2 - 5 } & & & & \\
\cline { 2 - 5 } & 1.0 & 1.7 & 1.4 & 3.1 \\
\hline -actin & & & & & \\
\cline { 2 - 4 } & &
\end{tabular}

$\operatorname{TSA}(1 \mu \mathrm{M}) \quad-\quad+\quad+$

Sorafenib $(10 \mu \mathrm{M}) \quad-\quad+\quad+$

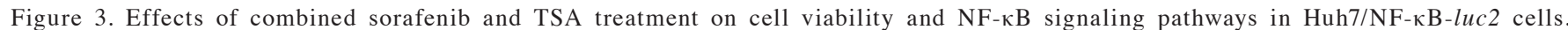
(A) Cytotoxicity was determined with an MTT assay ${ }^{* *} \mathrm{P}<0.01$ with comparisons indicated by lines. (B) The expression of NF- $\kappa \mathrm{B}$ was determined by bioluminescence imaging. ${ }^{* *} \mathrm{P}<0.01$ with comparisons indicated by lines. (C) Cells were pre-treated with MAPK inhibitors (10 $\mu$ M; PD98059, 1L-6-hydroxymethyl-chiro-inositol-2-(R)-2- $O$-methyl-3- $O$-octadecyl-sn-glycerocarbonate, SP600125 and SB203580 for $24 \mathrm{~h}$ followed by TSA (1 $\mu \mathrm{M})$ for a further $24 \mathrm{~h}$. The activation of NF-kB was determined by bioluminescence imaging ${ }^{* * *} \mathrm{P}<0.01$ vs. control, ${ }^{\# /} \mathrm{P}<0.01$ vs. TSA alone. (D) Cells were treated with sorafenib $(10 \mu \mathrm{M})$ for $48 \mathrm{~h}$, TSA $(1 \mu \mathrm{M})$ for $48 \mathrm{~h}$, and sorafenib $(10 \mu \mathrm{M})$ for $24 \mathrm{~h}$ followed by TSA $(1 \mu \mathrm{M})$ for $24 \mathrm{~h}$. Western blots for total and phosphorylated

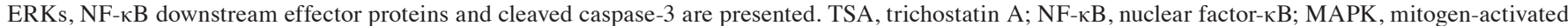
protein kinase; P-Phosphorylated; T-, total; ERK, extracellular-signal-regulated kinase; MMP-9, matrix metalloproteinase-9; VEGF, vascular endothelial growth factor; XIAP, X-linked inhibitor of apoptosis protein; Bcl-2, B-cell lymphoma 2; SO, sorafenib; MEKI, MAPK/ERK kinase inhibitor; AKTI, protein kinase B inhibitor; JNKI, c-Jun N-terminal kinase inhibitor; P38, p37 inhibitor.

The decreased $\Delta \Psi_{\mathrm{m}}$ and increased cleaved caspase-3 levels represent early and late events in the apoptotic processes, respectively $(26,27)$. These results suggest that inhibition of $\mathrm{NF}-\kappa \mathrm{B}$ activation and the expression of its downstream proteins by pretreatment of sorafenib may increase TSA-induced apoptosis and cell death. A previous study suggested that the radiosensitivity of HCC cells may be modulated by sorafenib in a schedule-dependent manner (28). Furthermore, concurrent treatment with radiation and sorafenib and pre-treatment of sorafenib were reported to improve the sensitizing enhancement ratio for human SMMC-7721 and SK-HEP-1 HCC cell lines, respectively (29). In another previous study, pretreatment of sorafenib combined with radiation resulted in improved therapeutic potential in three human $\mathrm{HCC}$ cell lines in vitro and in vivo (30). The basic strategy of combined chemotherapeutic drugs is to increase the treatment success, reduce the dosage of either drug, and ensure there is little or no increased toxicity to normal tissue. It was previously reported that a combination of two targeted drugs, Imatinib combined with Nilotinib or Dasatini, was able to improve the therapeutics of chronic myeloid leukemia (31). Our group have previously demonstrated that sorafenib combined with SAHA increased the therapeutic efficacy of HCC in vitro and in vivo, which demonstrated that $\mathrm{NF}-\kappa \mathrm{B}$ activity was decreased 2-fold yet increased 2-fold following treatment with SAHA $(10 \mu \mathrm{M})$ for 24 and $48 \mathrm{~h}$, respectively, therefore, the concurrent treatment which was identified to increase the therapeutic efficacy was used in the animal study (21). However, the sequence effects of combined SAHA and sorafenib treatment were not fully investigated in vitro. The combined enhanced antitumor effect of sorafenib and TSA treatment may be dependent on a sequence-dependent regime in HCC cells. Therefore, three combinations of sorafenib and TSA treatments were investigated, to identify the optimal treatment regime of HCC in vitro. 
Notably, cell viability was not affected by TSA combined with post-treatment of sorafenib compared with that of sorafenib treatment alone. However, sorafenib pretreatment exhibited increased cytotoxic effects compared with that of concurrent and post-treatment combinations with TSA. To the best of our knowledge, the present study is the first to demonstrate that combined sorafenib and TSA, most specifically pre-treatment with sorafenib followed by TSA, may prove to be a more effective therapeutic treatment for HCC.

PD98059, a MEK inhibitor, has been demonstrated to potentiate TSA-induced cell cycle arrest and apoptosis, and reverse TSA-induced ERK/NF- $\kappa \mathrm{B}$ activation in gastric cancer cells in vitro (14). Similarly, sorafenib has been revealed to enhance the therapeutic efficacy of SAHA through the suppression of SAHA-induced ERK/NF- $\kappa \mathrm{B}$ signaling pathways in $\mathrm{HCC}$, in vitro and in vivo (21). Notably, the results of the present study revealed that TSA-induced $\mathrm{NF}-\kappa \mathrm{B}$ activity was inhibited by sorafenib in Huh7/NF- $\kappa \mathrm{B}-l u c 2$ cells in a schedule-dependent manner through the suppression of the $\mathrm{MEK} / \mathrm{ERK} / \mathrm{NF}-\kappa \mathrm{B}$ signaling pathway.

Several previous studies have demonstrated that MAPK family members (ERK, JNK, p38 and AKT) activate NF- $\kappa$ B and the expression of its downstream effector proteins. In the present study, MEK, AKT, JNK and p38 inhibitors were used to verify the underlying molecular mechanisms of $\mathrm{NF}-\kappa \mathrm{B}$ downstream signaling involved in the cytotoxicity of TSA in Huh7/NF- $\kappa \mathrm{B}-l u c 2$ cells. The results revealed that pre-treatment with sorafenib or MEK inhibitor PD98059 significantly inhibited TSA-induced $N F-\kappa B$ activity. The TSA-induced ERK phosphorylation and the expression of $\mathrm{NF}-\kappa \mathrm{B}$ downstream effector proteins were inhibited by sorafenib pre-treatment combined with TSA.

The results of the present study demonstrated that the antitumor effects of combined sorafenib and TSA treatment in human hepatocellular carcinoma Huh7/NF- $\mathrm{B}-l u c 2$ cells are schedule-dependent. Sorafenib pre-treatment with TSA may be the optimal combination with the highest therapeutic efficacy via the suppression of the $\mathrm{MEK} / \mathrm{ERK} / \mathrm{NF}-\kappa \mathrm{B}$ signaling pathway. In conclusion, this strategy may have potential benefits for the treatment of advanced HCC in the clinic.

\section{Acknowledgements}

Not applicable.

\section{Funding}

The present study was supported by the Biophotonics and Molecular Imaging Research Center, Biomedical Engineering Research and Development Center, and the Ministry of Education, Aim for the Top University Plan, National Yang-Ming University, Taipei, Taiwan (grant no. 106AC-BI1); and the National Yang-Ming University Hospital, Yilan, Taiwan (grant no. RD2015-014).

\section{Availability of data and materials}

The datasets used and/or analyzed during the current study are available from the corresponding author on reasonable request.

\section{Authors' contributions}

JC, HC, FH and JH contributed to the conception and design of the study. JC, HC, YL and FH performed the experiments and wrote the first draft of the manuscript. JH organized the research, contributed to the revision of the manuscript and gave final approval of the version to be published. YC and WW made substantial contributions to the analysis and interpretation of the data and revised the manuscript critically for important intellectual content. YC and WW agreed to be accountable for all aspects of the work in ensuring that questions related to the accuracy or integrity of any part of the work are appropriately investigated and resolved. Each author has participated sufficiently in the work to take public responsibility for appropriate portions of the content.

\section{Ethics approval and consent to participate}

Not applicable.

\section{Patient consent for publication}

All authors consent for the publication.

\section{Competing interests}

The authors declare that they have no competing interests.

\section{References}

1. Pan LN, Lu J and Huang B: HDAC inhibitors: A potential new category of anti-tumor agents. Cell Mol Immunol 4: 337-343, 2007.

2. Mund C and Lyko F: Epigenetic cancer therapy: Proof of concept and remaining challenges. Bioessays 32: 949-957, 2010.

3. Rosato RR, Almenara JA and Grant S: The histone deacetylase inhibitor MS-275 promotes differentiation or apoptosis in human leukemia cells through a process regulated by generation of reactive oxygen species and induction of p21CIP1/WAF1. Cancer Res 63: 3637-3645, 2003.

4. Baradari V, Höpfner M, Huether A, Schuppan D and Scherubl H: Histone deacetylase inhibitor MS-275 alone or combined with bortezomib or sorafenib exhibits strong antiproliferative action in human cholangiocarcinoma cells. World J Gastroenterol 13: 4458-4466, 2007.

5. Ngamphaiboon N, Dy GK, Ma WW, Zhao Y, Reungwetwattana T, DePaolo D, Ding Y, Brady W, Fetterly G and Adjei AA: A phase I study of the histone deacetylase (HDAC) inhibitor entinostat, in combination with sorafenib in patients with advanced solid tumors. Invest New Drugs 33: 225-232, 2015.

6. Yuan H, Li AJ, Ma SL, Cui LJ, Wu B, Yin L and Wu MC: Inhibition of autophagy significantly enhances combination therapy with sorafenib and HDAC inhibitors (vorinostatin) for human hepatoma cells. World J Gastroenterol 20: 4953-4962, 2014.

7. Huang HL, Lee HY, Tsai AC, Peng CY, Lai MJ, Wang JC, Pan SL, Teng CM and Liou JP: Anticancer activity of MPT0E028, a novel potent histone deacetylase inhibitor, in human colorectal cancer HCT116 cells in vitro and in vivo. PLoS One 7: e43645, 2012.

8. Chen CH, Chen MC, Wang JC, Tsai AC, Chen CS, Liou JP, Pan SL and Teng CM: Synergistic interaction between the HDAC inhibitor, MPT0E028 and sorafenib in liver cancer cells in vitro and in vivo. Clin Cancer Res 20: 1274-1287, 2014.

9. Yao J, Duan L, Fan M and Wu X: NF-kappaB signaling pathway is involved in growth inhibition, $\mathrm{G} 2 / \mathrm{M}$ arrest and apoptosis induced by trichostatin A in human tongue carcinoma cells. Pharmaco Res 54: 406-413, 2006.

10. Zhang G, Park MA, Mitchell C, Hamed H, Rahmani M, Martin AP, Curiel DT, Yacoub A, Graf M, Lee R, et al: Vorinostat and sorafenib synergistically kill tumor cells via FLIP suppression and CD95 activation. Clin Cancer Res 14: 5385-5399, 2008. 
11. Duvic M and Vu J: Update on the treatment of cutaneous T-cell lymphoma (CTCL): Focus on vorinostat. Biol Targets Ther 1: 377-392, 2007.

12. Coradini D and Speranza A: Histone deacetylase inhibitors for treatment of hepatocellular carcinoma. Acta pharmacol Sin 26: 1025-1033, 2005.

13. Yan G, Graham K and Lanza-Jacoby S: Curcumin enhances the anticancer effects of trichostatin a in breast cancer cells. Mol Carcinogen 52: 404-411, 2013.

14. Yao J, Qian CJ, Ye B, Zhang X and Liang Y: ERK inhibition enhances TSA-induced gastric cancer cell apoptosis via NF- $\kappa \mathrm{B}-$ dependent and Notch-independent mechanism. Life Sci 91: 186-193, 2012.

15. Tai DI, Tsai SL, Chang YH, Huang SN, Chen TC, Chang KS and Liaw YF: Constitutive activation of nuclear factor kappaB in hepatocellular carcinoma. Cancer 89: 2274-2281, 2000.

16. Li W, Tan D, Zenali MJ and Brown RE: Constitutive activation of nuclear factor-kappa B $(\mathrm{NF}-\kappa \mathrm{B})$ signaling pathway in fibrolamellar hepatocellular carcinoma. Int J Clin Exp Patho 3: 238-243, 2010.

17. Wang WH, Chiang IT, Liu YC, Hsu FT, Chen HW, Chen CL, Lee YJ, Lin WJ and Hwang JJ: Simultaneous imaging of temporal changes of NF- $\mathrm{BB}$ activity and viable tumor cells in Huh7/NF-kappaB-tk-luc2/rfp tumor-bearing mice. In Vivo 27: 339-350, 2013.

18. Pan CC, Kavanagh BD, Dawson LA, LI XA, Das SK, Miften M and Tan RK: Radiation-associated liver injury. Int J Radiat Oncol 76 (Suppl): S94-S100, 2010.

19. Liu YC, Chiang IT, Hsu FT and Hwang JJ: Using NF-кB as a molecular target for theranostics in radiation oncology research. Expert Rev Mol Diagn 12: 139-146, 2012.

20. Dai Y, Guzman ML, Chen S, Wang L, Yeung SK, Pei XY, Dent P, Jordan CT and Grant S: The NF (Nuclear factor)-kappaB inhibitor parthenolide interacts with histone deacetylase inhibitors to induce MKK7/JNK1-dependent apoptosis in human acute myeloid leukaemia cells. Brit J Haematol 151: 70-83, 2010

21. Hsu FT, Liu YC, Chiang IT, Liu RS, Wang HE, Lin WJ and Hwang JJ: Sorafenib increases efficacy of vorinostat against human hepatocellular carcinoma through transduction inhibition of vorinostat-induced ERK/NF- $\mathrm{EB}$ signaling. Int $\mathrm{J}$ Oncol 45 : $177-188,2014$
22. Chiang IT, Liu YC, Wang WH, Hsu FT, Chen HW, Lin WJ, Chang WY and Hwang JJ: Sorafenib inhibits TPA-induced MMP-9 and VEGF expression via suppression of ERK/NF- $\kappa B$ pathway in hepatocellular carcinoma cells. In Vivo 26: 671-681, 2012.

23. Kuo YC, Lin WC, Chiang IT, Chang YF, Chen CW, Su SH, Chen CL and Hwang JJ: Sorafenib sensitizes human colorectal carcinoma to radiation via suppression of $\mathrm{NF}-\kappa \mathrm{B}$ expression in vitro and in vivo. Biomed Pharmacother 66: 12-20, 2012.

24. Meidhof S, Brabletz S, Lehmann W, Preca BT, Mock K, Ruh M, Schüler J, Berthold M, Weber A, Burk U, et al: ZEB-1 associated drug resistance in cancer cells is reversed by class I HDAC inhibitor mocetinostat. EMBO Mol Med 7: 831-847, 2015.

25. Rundall BK, Denlinger CE and Jones DR: Combined histone deacetylase and NF-kappaB inhibition sensitizes non-small cell lung cancer to cell death. Surgery 136: 416-425, 2004.

26. Domingo-Domenech J, Pippa R, Tapia M, Gascon P, Bachs O and Bosch M: Inactivation of NF-kappaB by proteasome inhibition contributes to increased apoptosis induced by histone deacetylase inhibitors in human breast cancer cells. Breast Cancer Res $\operatorname{Tr}$ 112: 53-62, 2008

27. Ly JD, Grubb DR and Lawen A: The mitochondrial membrane potential (deltapsi(m)) in apoptosis; an update. Apoptosis 8: 115-128, 2003.

28. Li Q, Hu Y, Xi M, He L, Zhao L and Liu M: Sorafenib modulates the radiosensitivity of hepatocellular carcinoma cells in vitro in a schedule-dependent manner. BMC Cancer 12: 485, 2012.

29. Yu W, Gu K, Yu Z, Yuan D, He M, Ma N, Lai S, Zhao J, Ren Z, Zhang X, et al: Sorafenib potentiates irradiation effect in hepatocellular carcinoma in vitro and in vivo. Cancer Lett 329: 109-117, 2013.

30. Chen J CH, Chuang HY, Hsu FT, Chen YC, Chien YC and Hwang JJ: Sorafenib pretreatment enhances radiotherapy through targeting MEK/ERK/NF- $\mathrm{B}$ pathway in human hepatocellular carcinoma-bearing mouse model. Oncotarget, 2016 (in press).

31. Komarova NL, Katouli AA and Wodarz D: Combination of two but not three current targeted drugs can improve therapy of chronic myeloid leukemia. PLoS One 4: e4423, 2019. 